\title{
Research into medical accidents: a case of negligence?
}

\author{
C A Vincent
}

Public awareness of medical accidents is growing, as the rapidly rising rate of litigation and the corresponding increase in defence society subscriptions testify.' In many activities - for example, aviation, road and rail travel, industry - errors and accidents are the object of systematic study. ${ }^{2-4}$ Aircraft accidents are extensively investigated and extraordinary measures taken to minimise the risks of air travel. The risk of death under anaesthesia is comparable to the risk of accident on a commercial flight. ${ }^{5}$ Yet in anaesthesia, and medicine generally, accidents are seldom discussed publicly and few studies are conducted. Many doctors do, of course, review their work in morbidity and mortality meetings. This does not usually extend to systematic study, however, and the results are not usually communicated to the wider medical community. I suggest here that research into medical accidents has been greatly neglected but that accidents can and should be studied.

\section{Accidents, errors, and negligence}

A consistent finding in all accident research is that the main cause of accidents is human error, ${ }^{6}$ often compounded by organisational factors. ${ }^{78}$ Even catastrophes such as the accidents at nuclear power plants at Chernobyl and Three Mile Island were the result not of unusual circumstances but of quite ordinary slips and lapses. ${ }^{9}$ Assuming some parallels with other areas, two points can be made about the study of medical accidents. Firstly, the main focus of investigation should be on the actions of those concerned, rather than on patient characteristics or technical faults. Secondly, the study of medical accidents should include errors and near misses (cases where an accident was narrowly averted).

Error does not necessarily imply negligence. Some accidents involve negligence, but most do not. Researchers should in any case not assess negligence, for three reasons. Firstly, few medical errors are likely to involve negligence; secondly, cooperation can be expected only if researchers treat information obtained as confidential;thirdly, the assessment of negligence is (ultimately) a matter for the courts. Blame, if any, should be assessed separately from cause and by people other than researchers.

\section{Studies of medical accidents}

This section provides a brief overview of research relevant to medical accidents. The examples cited are scattered studies and do not indicate a coherent body of research. The most striking finding is the paucity of the literature.

\section{SEARCHING THE LITERATURE}

Index Medicus classifies accidents under several headings according to whether they occur in the home, at work, in the air, or on the roads. There are also

Department of Psychology, University College, London WC1E 6BT

C A Vincent, PHD, lecturer in psychology applied to medicine

BrMed f 1989;299:1150-3 emphasis is on packaging and the consequences of medication errors. The authors of the few papers discussing the actual errors are usually pharmacists or nurses. ${ }^{10-13}$

\section{INCIDENCE}

Official statistics are collected on many forms of accidents, but little is known about the overall incidence of medical accidents in the United Kingdom. The protection societies have information on the annual rate of claims and complaints, but this is only a fraction of the total number of accidents, many of which will not involve negligence. The Harvard medical practice study ${ }^{14}$ will shortly provide detailed information on the incidence of medical accidents and negligence in New York State. The only published information, however, comes from a study conducted in California in 1974 . Three million hospital admissions led to 140000 injuries, 24000 being due to negligence. ${ }^{15}$ With five million hospital admissions a year in England alone ${ }^{16}$ this might mean as many as 230000 medical accidents in English hospitals, some 40000 being due to negligence.

\section{CONFIDENTIAL INQUIRIES}

The confidential inquiries into deaths during childbirth, anaesthesia, and surgery ${ }^{17-19}$ did not specifically set out to study medical accidents (that would have been prejudging the issue). Nevertheless, all have found that a high proportion of the deaths were avoidable, some associated with substandard care. For instance, the delegation of high risk obstetric operations to registrars appears to have contributed to several deaths. ${ }^{17}$ The reasons for this can, however, only be guessed at. The delegation might have been due to staff shortages, overconfidence on the part of the registrar, inadequate supervision by the consultant, or a failure of communication between registrar and consultant. Only more detailed studies will reveal the causes of such accidents-and provide effective methods of prevention.

\section{FROM MEDICAL RECORDS}

When a case is brought against a doctor an expert opinion, based on an examination of the case notes, is sought by both defence and prosecution. These expert opinions have been used in a recent study at the Medical Protection Society examining the nature of obstetric accidents judged to have led to brain damage in babies (M Ennis and C A Vincent, unpublished, 1989). Common contributory causes identified were a lack of supervision and cover by senior staff and the inexperience of junior doctors in the use of forceps and fetal heart monitoring. Such studies can usefully point to areas of concern, but suffer from certain limitations (discussed below).

\section{AUDITS}

Accidents and errors may be shown in the course of routine audits, even though this is not their primary purpose. Most audits stop short of identifying mistakes, or at least stop short of publishing the information. There are, however, some important exceptions. Dearden and Rutherford carried out a prospective misuse, presumably relating to human error, but few papers are listed. A section on medication error provides some useful information, but even here the 


\section{A typical accident}

This, fictional, example is based on cases reviewed in the Medical Protection Society survey of obstetric accidents. It could, of course, be set in any specialty.

A senior house officer is responsible for a woman in labour. The fetal heart is being monitored, and the trace seems to his (inexperienced) eye to be normal. The midwife suspects that it is abnormal and suggests he ask for an opinion. He is reluctant to take her advice (she is also fairly junior) and equally reluctant to wake the registrar, who was distinctly irritated at being unnecessarily disturbed a few hours previously. The senior house officer moves to another patient, planning to return in 10 minutes, but is delayed by a telephone call. By the time he returns the trace is almost flat, and it is obvious that the baby is distressed. He calls the registrar, who in the mean time has been called to the paediatric ward, which she is also covering owing to staff shortages. She comes as soon as she can and arranges an immediate caesarean, but the baby is by now hypoxic and is later found to be brain damaged. A catastrophic outcome, undeniably accidental. There is no single cause, and it is not obvious that the senior house officer should be considered negligent.

Many factors contributed to this accident. Firstly, there is the senior house officer's lack of obstetric experience; secondly, his possibly deficient training in fetal heart monitoring; thirdly, the factors that led him to misinterpret this particular trace (Was he misled by other clinical signs for instance, or did he fail to take them into account?); fourthly, the attitude of the senior house officer to the midwife, which led him to disregard her advice; fifthly, his nervousness at the prospect of waking the registrar; sixthly, the staff shortages, which led to the registrar covering two units. There are also a host of potential background factors, some psychological (mood, fatigue, distressing events in the doctors' lives) and social or organisational (allocation of resources, management decisions on staffing and training). study of the treatment of severe trauma. ${ }^{20}$ Common problems identified were missed or delayed diagnosis, a failure to recognise that treatment was necessary, and an inability to carry out a necessary treatment. This study was conceived as an internal audit, but the authors thought that the findings were sufficiently important to merit publication.

\section{STUDIES OF ERRORS}

Many studies attest to the fact that errors in medicine are common. High rates of error have been found in detecting the clinical signs of cyanosis, interpreting electrocardiograms and radiographs, taking a history, and assessing biopsy specimens in the laboratory. ${ }^{21}$ Comparisons of diagnoses with necropsy results ${ }^{2223}$ or of initial diagnoses with final diagnoses also show high levels of inaccuracy. ${ }^{24}$ Inaccurate diagnoses and test results do not necessarily imply human error, but they do show that the practice of medicine can be a very uncertain process. ${ }^{21}$ Few studies focus directly on errors, though such investigations are both feasible and valuable. For instance, Cooper and his colleagues reviewed 1089 potentially dangerous incidents in anaesthesia. ${ }^{5}$ They classified most errors into failures of technique, errors of judgment, and lapses of attention and made many recommendations for improved patient care. The authors commented that previous studies of anaesthetic risk looked only at patient characteristics and equipment. They emphasised the need to study the actions of the anaesthetists - the human factor.

\section{THE CAUSES OF ERROR}

Studies of medical errors are rare; studies of their causes are even rarer. This neglect is striking when one considers, for instance, the widespread concern about junior doctors' working hours. ${ }^{26}$

Many junior doctors believe that their judgment is impaired by fatigue. Studies have shown significant impairments in cognitive functioning after sleep deprivation, with less clear deficits shown in the performance of simulated medical tasks. ${ }^{2728}$ The effect of fatigue on actual task performance, however, and the consequent effect on patient care seems not to have been examined. ${ }^{29}$ Similarly, the effect of other types of stress on patient care can only be guessed at, though the level of psychological disturbance in junior doctors is beginning to be appreciated. ${ }^{30-32}$

\section{Understanding medical accidents}

Explaining any piece of behaviour is complex. Accidents and errors, departures from ordinary behaviour, are still more difficult to explain. Accidents are multiply determined; as the example shows (see box), it is rarely possible to identify a single, overriding cause.

How should we approach the study of such a complex phenomenon? Firstly, we need to obtain detailed descriptions of actual accidents or errors, secondly, to classify any errors made, and, thirdly, to identify their causes.

\section{Descriptive studies of accidents}

Studies from records are a valuable starting point, but they do have weaknesses. Records are often inadequate and sometimes misleading. ${ }^{334} \mathrm{~A}$ more fundamental problem is that records seldom give any clues about the causes of accidents and errors. An expert may be able to point to inadequacies in patient management but can usually only guess why these have occurred. Similar problems have affected workers studying reports of other kinds of accidents. ${ }^{35}$ Studies which ask specific questions of those involved are potentially much more valuable.

An ideal method is the critical incident technique. ${ }^{36}$ Critical incidents are events in medical practice where actions by the physician had a clear beneficial or detrimental effect on the patient. In medicine the technique has mostly been used for defining clinical competence. It can, however, also be used to investigate errors, as the study by Cooper $e$ al on anaesthetic incidents well shows. ${ }^{5}$ Once data are collected they must next be interpreted and classified.

\section{Classifying errors and accidents}

The type of errors observed will vary according to the speciality, the task, and the people. Cooper et al classified anaesthetic errors into technical, judgmental, and those concerning monitoring and vigilance. ${ }^{5}$ In studying diagnostic errors Gruver and Freis looked at lack of adequate history, errors of omission, errors of judgment, misleading test results, and problems with the physical examination. ${ }^{37}$ Two types of classification are confused in both these studies. One specifies the type of activity (monitoring, taking a history) where errors were made. The second classification is based on the psychological processes-judgment, attention (vigilance), memory (omitting a routine procedure). Both approaches are valuable, but they should be separated. A third approach is simply to classify errors according to the most effective way of preventing them ${ }^{35}$ - for example, by providing standing orders or clinical algorithms. The classification that is most 
useful will depend on the purpose of the investigation Immediate changes in training priorities might result from simply identifying the medical tasks where most errors are made.

A distinction that has important implications for prevention is between errors that are due to deficient knowledge and those that concern performance. Education and training will improve knowledge but may not affect medical practice. Our own study of obstetric accidents showed that some were due to junior doctors acting beyond their competence. This is not a failure of knowledge but a failure of judgment of their own abilities.

\section{Identifying causes}

Contributory causes may be studied in relation to both errors and accidents. Previous accident research suggests that it is more profitable to relate causal factors to errors, or particular tasks or skills, rather than accidents. ${ }^{38}$ Thus it is more profitable to look at the relation between fatigue and the ability to interpret fetal heart traces than attempt to (retrospectively) investigate fatigue in people involved in obstetric accidents.

The following are some potentially important factors.

Personal characteristics-Accident researchers have abandoned the search for an accident prone personality. ${ }^{39}$ Nevertheless, some individuals may make more errors than others at particular times or in particular circumstances. Some tentative evidence suggests that high anxiety levels or depression may predispose to error.$^{28}{ }^{40}$ Other important characteristics in a medical setting might be overconfidence, ${ }^{41}$ willingness to make risky decisions, and basic clinical competence.

Transient states-The effect of drugs and alcohol on errors and safety is the dominant concern in road safety ${ }^{42}{ }^{43}$ and important in many areas of accident research. There have been some worrying studies of the level of alcohol consumption by a minority of doctors ${ }^{44}{ }^{45}$ but its effect on their work is unknown. Other obvious contenders for investigation are fatigue and mood.

Patient characteristics-The patient's particular combination of signs and symptoms and history can certainly influence the liability to error. For instance, clinicians tend to misinterpret test results from patients who have an already established disease. ${ }^{46}$ Factors that affect communication between doctor and patient may also be important. Diagnostic errors might, for example, be more likely if patient and doctor do not share the same first language.

Organisational factors-Organisational factors, even the wider economic and political environment, may be implicated in some medical accidents. Poor staffing, for instance, leads to overworked staff, fatigue, and possible error. Nothing short of political change may alter such a situation. Shift patterns, workload, and carrying out several tasks at once have all been found to increase errors in other settings. ${ }^{478}$ Administrative factors may influence the availability of test results and records, the ease of communication between team members, the availability of necessary staff, and so on.

\section{Why study medical accidents?}

Understanding and prevention-The best reason for studying errors and accidents, and their causes, is that it may help prevent them. Errors may not always lead to accidents but will often cause unnecessary distress, delay to patients and staff, wasting of time, additional expense, and a whole range of minor inconveniences that adversely affect health care. Any systematic attempt to reduce error should have widespread consequences.

Facilitating learning-Studying and being aware of errors in clinical practice has another benefit, as McIntyre and Popper point out: it facilitates learning. ${ }^{49}$ Psychologists would accord awareness of errors a similar importance but characterise it as a form of feedback. Unless one has feedback on one's own performance (in any task) there is little hope of correcting errors or of improving performance.

Understanding medical thinking-There is already a considerable body of academic knowledge on medical judgment and decision making, much of it concerned with biases, errors, and suboptimal strategies. Much of this work has been criticised as being too artificial to be useful to the clinician. ${ }^{50}$ Information on errors made in actual practice might permit some of these hypotheses to be evaluated; theoretical work might suggest the causes of some of the errors once they are described.

Public confidence-Medical accidents must not only be investigated but be seen to be investigated. Public confidence in air travel is increased by the extensive investigations of accidents and the apparent determination of airlines to learn from their mistakes. Yet in medicine there is little public acknowledgment of mistakes. Patients who are the victims of medical accidents often experience great difficulty in finding out what went wrong..$^{51}$ Failure to receive an explanation appears to be a factor in a decision to proceed to litigation in at least some cases. ${ }^{48} \mathrm{We}$ need to know much more about how medical accidents are handled and what the consequences are for the patients concerned.

\section{Recommendations}

The most pressing need is for epidemiological and descriptive studies of medical accidents. The Harvard study has assessed the incidence of accidents, negligence, litigation, and levels of compensation in the United States. ${ }^{14}$ We need a parallel study in the United Kingdom to identify common accidents and assess the needs of the patients concerned. Such a study would also provide an estimate of the cost of no fault compensation. The debate on no fault schemes is, to say the least, considerably hampered by an almost total lack of information on the likely cost of the various options.

If audits are to be serious attempts to enhance the quality of medical care they must examine occasions where things went wrong. As yet few audits report substandard care or adverse consequences of treatment. Future audits and confidential inquiries should incorporate specific questions about errors, accidents, and their causes.

Critical incident studies and analyses of records of medical accidents are needed in all specialties to provide more detailed accounts and identify common themes. Our own experience of analysing records is that patterns rapidly emerge, drawing attention to deficiencies in training, supervision, clinical abilities, organisation, and communication. Accidents are often symptomatic of wider problems. Far from being isolated disasters, an analysis often suggests that there is a potential for many more such incidents.

I thank Dr I C McManus and Ms M Ennis for their comments on an earlier draft.

The paper forms part of the Medical Protection Society research project on avoidable mishaps in medicine under the direction of Professor R J Audley.

1 Smith R. Middle way for negligence. Br Med f 1988;297:641.

2 Ricketson DS, Brown WR, Graham KN. 3W Approach to the investigation of analysis and prevention of human error. Avial Space Environ Med 1980;51 $1036-42$

3 McKenna FP. The human factor in driving accidents: an overview of approaches to problems. Ergonomics 1982;10:867-77. 


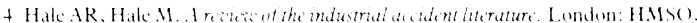
197

S Couper JB Vewbower RS, Kile RJ. An analwis of maior crrors and courment fulures in anesthesia management Considerations for prevention and detcition. Anesthestology 1984:60:34-42.

6 Sivak M. Iluman facters and highway accident causation: Some theoreticat consderations. Acodent Analyos and l'recentom 1981:13:61-4

Turner BA. Man-made disasters. 1,ondon: Wukcham Publications, 1978

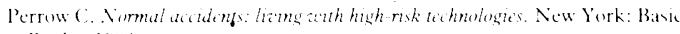
Berks, 198-

9 Reason J. Aheent-mindedness and cognitive control. In: Harri JE, Morris l'P:

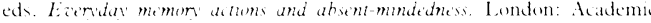
Press, 198.t:113.31.

10 Anderson RD). The phesician' contribution to hospital medication crrors Am f How Pharm 1971:28:18:25.

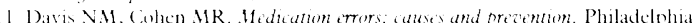

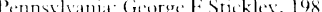

12. Long (i. The effect of medication distribution sistems on medication errors. Vurs $R_{i}=1982: 31: 182-4$

Is Bet\% RP. L.cW HB. An interdisciplinare methed of chassifing and menitorine medication crrors. im 7 Hosp Pharm 1985:42:1724-32.

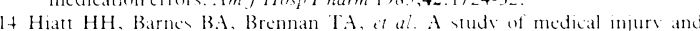
malpractice. Neciel lingl Y Hed 1989:321:480-t

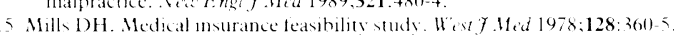

16 Department of Health and Secial Security. Hesplual inpatient enyury summer tablis. London: H.Miso, 1985

17 Office of Population Censuses and Survers. Report on comfutentul enquires

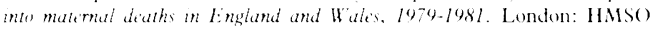
1986

Ix Lunn JN. Mushin WW. Mortalut assoctutid with andesthesta. Iondon: . Nufficld P'roninctial Hospitals Trust, 198

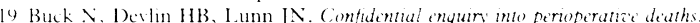
Londen: Nuffictd Procincial Hospitals Trust, 1987.

20) Dearden CH, Kutherford WH. The resuscitation of the severely injured in the accident and emergency department a medical audit. Inhury 1985:16 249.52

21 Eddy DM. Variations in phesician practice: the role of uncertaints. In: Dowic

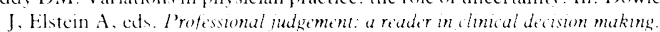
Cambridge: Cambridge Unisersits Press, 1988

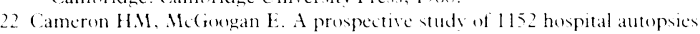
I1. Anakso in inaccuracies in clinical diagneses and their significance. 7 l'athol 1981:133:285-300)

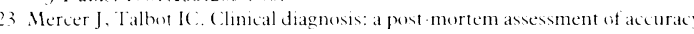

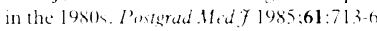

24 Adams ID, Chan M. Clifford PC et al. Computer aided diagnesis of acute ahdominal pain: at multicentre studv. Br.11ed 7 1986:293:800-4.

25 Driscoll PA. Vincent CA, Servant CJ, Audlex RJ. Use of advisers in the diagnosis and mathatement of abdominal pain in accident and emergenci departments, Bry Sur: 1988:75:1173-5

26 Durnford S. Junor heopulal dectors: tired and tested. Br. Hed 7 1988:297.

Deary IJ. Tate R. Beffects of sleep disruption on cognitive performance and mond in medical houre ufficers. Br Hed 7 1987:295:1513-6.
28 (Oron DI. (irucclier JH Adverse changes in mond and cognitie performance of house offlicers after night dutw. Br. 11tid $71989: 298: 21-3$

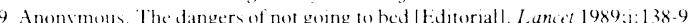
30 Firth-Cozens J. Emotional distress in iunier house officers. Br Med $1987,295: 533-6$

1 Pillowski L. ('Sullivan (i. Mental illness in doctors. Br Med f 1989:298 269.70

32 Cooper CI, Rout L, Faragher B. Mental health, joh satisfaction, and joh stress ameng general practitioners. Br.14: 7 1989;298:366-70.

Swansea Physcians" Audit Group. Audit of the qualits of medical records in a district general medicine unit. F $R$ Coll Physctums Lond 1983;17:208-12.

it Mansfield BC. How had are medical records? A review of the notes received hy a practice. 7 R (.oll (ien Pract 1986;36:405-6.

35 Leplat J. Rasmussen I. Analssis of human crrors in industrial incidents and accidents for improvement of work satets. Accid Anal Prea 1984:16:77-88.

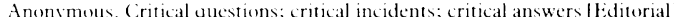
Lancet 198x:i:1373-4.

37 (iruser RH, Freis ED. A study of diagnestic errors. Ann Inem lled 1957:47:119-20.

38.11 K Kenna Fl' Duncan J. Brown ID Cognitive abilities and safetr on the road a re-examination of indicidual differences in dichotic listening and search for cmbedded tigures. Lirgonomics 1986:29:649-63.

39 McKenna FP. Accident proneness: a conceptual analssis. Aicd inal Pret $1981: 15: 65-71$

40) Ersenck MW . Atentwon and arousal. New York: Springer-Verlag, 1982.

1 Marteau TM, Winne (i, Kaye W, Rvans TR. Resuscitation: experience without feedback increases confidence but not skill. Br. Med 71989 in press

2 McKenna, FP. Beharioural aspects of single-vehicte accidents. Trufte Enginetring and Control 1987;28:2801-5.

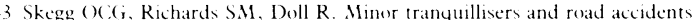
Br. Hidf 1979:1:917-9

H Lew $\mathrm{R}$. Alcoholism in house staff phrsicians: an occupational hazard. f()cup. 11:d 1986:28:79-81

5 Juntunen J, $A$ s S. Oikinuora $M$, Aarimaa $M$, Strid L, Kautu K. Dector drinking habits and consumption of alcohol. Br. 11ed f 1988:297:951-4.

46 Balla JI. Iansck R, Elstein A. Bavesian diagnosis in presence of pre-existing discasc. Lund 1985;1:326-9.

47 Colquhoun WP, Rutentrane J Studios of shetriork London: Taylor and Francis, 1980.

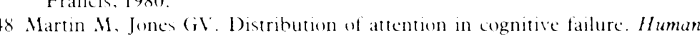
Léurming 1983:2:221-6

t9. Mentyre N. Popper $K$. The Critical attutude in medicine: the need for a new cthics Br.11:d 7 1983:287:1919-23

50 Christiansen-Szalanski JJJ, Buskrhead JBN. P'hysicians' use of probahilistic information in a real clinical setting. In: Dowie J, Elstein A. Professiomal judgement: a reuder in clincial decision making. Cambridge: Cambridge University P'ress, 1988:360)-73.

5 Simanowite $A$. Standards, attutudes and accountability in the medical profession. Lancel 1985;11:546-7.

Accopled 12 Siplember 1989

\section{Edinburgh Breast}

Screening Project

M Maureen Roberts, clinical

director

Correspondence to: Dr Joan

Austoker, CRC Breast

Screening Primary Care

Education Initiative,

Department of Community

Medicine and General

Practice, 2 Polstead Road.

Oxford OX2 6TN.

Br.Heity 1989:299:1153-5

\section{Breast screening: time for a rethink?}

\section{Maureen Roberts}

Dr M Maureen Roberts, clinical director of the Edinburgh Breast Screening Project since 1979, died of breast cancer on 9 Fune. We publish below her reflections on the care and welfare of women with the disease in Britain today, written shortly before her death. The list of references was added by the editor.

I am in reflective mood as I lie here in the sunshine at the end of my life. Breast cancer has caught up with me, after eight good years. It seems a common disease in Britain, and the evidence is strong that it is on the increase. Small wonder that people working with the disease desperately want to do something. Currently the main effort is in breast screening, with millions of pounds being put into a national programme, as recommended by the working group chaired by Professor Sir Patrick Forrest.

\section{What's the use of breast screening?}

I want to put the question, Are we going the right way to provide the best possible benefit?

First of all, screening is alwavs a second best, an admission of failure of prevention or treatment. As wo are unlikely to be able to prevent the disease what is required is successful treatment-and I don't mean even more aggressive adjuvant chemotherapy: I mean a treatment which works, which offers some kind of normal life. I don't want half promises of several years or a $50 \%$ chance of cure after surgery - it simply isn't good enough for women with the disease. As an example, Lippman believes that breast cancer could be the next human cancer capable of treatment and is working on innovative measures based on growth factors.' Others are using genetic approaches.

The next point to consider is, What can screening actually achieve? Two randomised trials, the Health Insurance Plan and the Swedish two county trial, showed a reduction in mortality of $30 \%$ in women offered screening. " Other trials, such as the Malmö, United Kingdom, and Edinburgh (unpublished) trials, found a non-significant reduction in mortality. We cannot ignore them, and it is not enough to say that our techniques weren't good enough a few years ago but are adequate now. We all know that mammography is an unsuitable screening test: it is technologically difficult to perform, the pictures are difficult to interpret, it has a high false positive rate, and we don't know how often to carry it out. We can no longer ignore the possibility that screening may not reduce mortality in women of any age, however disappointing this mav be.

Another problem is that screening is offered to only the small proportion of women aged 50-64, there being no evidence that it is of benefit to other women. When we calculate the number of women likely to benefit each year we find that it is a surprisingly small 